\title{
Differential Effects of Angelicin Analogues on NF- $\kappa$ B Activity and IL-8 Gene Expression in Cystic Fibrosis IB3-1 Cells
}

\author{
Ilaria Lampronti, ${ }^{1}$ Maria Giulia Manzione, ${ }^{1}$ Gianni Sacchetti, ${ }^{1}$ Davide Ferrari, ${ }^{1}$ \\ Susanna Spisani, ${ }^{1}$ Valentino Bezzerri, ${ }^{2}$ Alessia Finotti, ${ }^{1}$ Monica Borgatti, ${ }^{1}$ \\ Maria Cristina Dechecchi, ${ }^{3}$ Giorgia Miolo, ${ }^{3}$ Giovanni Marzaro, ${ }^{4}$ Giulio Cabrini, ${ }^{3}$ \\ Roberto Gambari, ${ }^{1,5}$ and Adriana Chilin ${ }^{4}$ \\ ${ }^{1}$ Department of Life Sciences and Biotechnology, University of Ferrara, Via Fossato di Mortara 74, Ferrara, Italy \\ ${ }^{2}$ Department of Medicine, University of Verona, Strada le Grazie 8, Verona, Italy \\ ${ }^{3}$ Department of Pathology and Diagnostics, Laboratory of Molecular Pathology, University Hospital of Verona, Verona, Italy \\ ${ }^{4}$ Department of Pharmaceutical and Pharmacological Sciences, University of Padova, Via Marzolo 5, Padova, Italy \\ ${ }^{5}$ Center of Biotechnology, University of Ferrara, Via Fossato di Mortara 64/b, Ferrara, Italy
}

Correspondence should be addressed to Ilaria Lampronti; lmi@unife.it and Roberto Gambari; gam@unife.it

Received 16 March 2017; Revised 14 July 2017; Accepted 6 August 2017; Published 27 September 2017

Academic Editor: Maria Rosaria Catania

Copyright (c) 2017 Ilaria Lampronti et al. This is an open access article distributed under the Creative Commons Attribution License, which permits unrestricted use, distribution, and reproduction in any medium, provided the original work is properly cited.

\begin{abstract}
The angelicin analogue 4,6,4'-trimethylangelicin (TMA) was recently reported as a strong inhibitor of nuclear factor- $\kappa \mathrm{B}$ (NF- $\kappa \mathrm{B}$ ) activity and of the expression of the interleukin-8 (IL-8) gene in bronchial epithelial cells in which the inflammatory response has been challenged with $P$. aeruginosa, the most common bacterium found in the airways of patients affected by cystic fibrosis (CF). These findings encouraged us to analyze new synthetic analogues of TMA in order to evaluate their biological activities on human bronchial epithelial CF IB3-1 cells and to find more potent anti-NF- $\kappa$ B agents exhibiting only minor antiproliferative effects. Analogues able to inhibit NF- $\kappa \mathrm{B} / \mathrm{DNA}$ interaction at lower concentration than TMA were found and selected to investigate their biological activity on IB3-1 cells induced with TNF- $\alpha$. In this biological system, NF- $\kappa \mathrm{B}-$ mediated IL- 8 gene expression was investigated. Some analogues showed similar activity to the lead compound TMA. Other analogues displayed higher activities; in particular, the most interesting compounds showing relevant anti-inflammatory effects were found to cause $56-83 \%$ reduction of IL-8 mRNA expression at low concentrations $(1-10 \mu \mathrm{M})$, without changes in cell proliferation pattern, demonstrating their potential interest for a possible development of anti-inflammatory therapy of cystic fibrosis.
\end{abstract}

\section{Introduction}

Psoralens, also known as furocoumarins, are naturally occurring or synthetic tricyclic aromatic compounds, deriving from the condensation of a coumarin nucleus with a furan ring $[1,2]$. The furan moiety may be fused in different ways producing several isomers: linear isomers (psoralens; Figure 1(a)) and angular isomers (angelicins, Figure 1(b); allopsolarens, Figure 1(c)) [3]. The most abundant linear furocoumarins are psoralen, xanthotoxin, and bergapten; whereas the angular type is mostly represented by angelicin [3].
Furocoumarins are found in natural plant extracts belonging to angiosperm families, formerly used in popular medicine: for example, angelicin is present in Angelica archangelica (Apiaceae), allopsoralen in Mammea americana (Guttiferae), and psoralens in Psoralea corylifolia (Leguminosae) and Amni majus (Apiaceae) [4-6]. Bergapten is found in Citrus bergamia (Rutaceae) [7].

At present, several psoralens are used also in conventional medicine in the treatment of various skin diseases (mainly vitiligo and psoriasis) [8], using PUVA therapy (Psoralen plus UVA light) [9]. The natural angular angelicin (ANG), used in folk medicine, and its synthetic derivative 


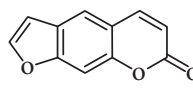

(a)

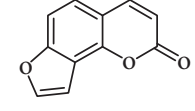

(b)

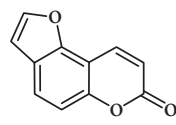

(c)
Figure 1: Chemical skeleton of linear and angular furocoumarins.

4,6,4'-trimethylangelicin (TMA) were described in recent studies of our research group $[10,11]$. TMA was found to be potentially useful in the treatment of cystic fibrosis (CF), thanks to its anti-inflammatory activity and its potentiating action on the CFTR membrane channel whose dysfunction causes that disease. Moreover, TMA resulted to be a new corrector, showing actually a third pharmacological activity $[12,13]$.

Cystic fibrosis, a genetic disease that primarily affects the lungs and digestive system, is the most common autosomal recessive disease in Caucasians associated with early death $[14,15]$; it is a complex multisystem disease caused by defects in a single gene that is CFTR (cystic fibrosis transmembrane conductance regulator), which encodes for a chloride channel expressed in several epithelia [16]. Pulmonary inflammation is responsible for most of the morbidity and mortality because the most important clinical complication is focalized in the airway tract of affected patients $[17,18]$. In the healthy lung, CFTR is detectable on the apical membrane of ciliated cells within the gland ducts and in the superficial epithelium of healthy individuals. In CF, the submucosal glands and distal airways are obstructed by thick tenacious secretions, resulting in a failure of normal mucociliary clearance and defective airway defense mechanisms against inflammation and bacterial infection. Therefore, inhibition of the proinflammatory pathways in CF appears to be clinically relevant [19-21].

In this context, the contribution of nuclear factor-kappaB $(\mathrm{NF}-\kappa \mathrm{B})$ in chronic inflammatory and autoimmune diseases is well known in CF. The activation of NF- $\kappa \mathrm{B}$ triggers proinflammatory cytokine production $[22,23]$. Therefore, targeting $\mathrm{NF}-\kappa \mathrm{B}$ might be a very interesting strategy in $\mathrm{CF}$, since NF- $\kappa$ B has been firmly linked to the IL-8 (interleukin-8) gene expression [24], which is a key chemokine activated in Pseudomonas aeruginosa induction of state of CF lung. Targeting $\mathrm{NF}-\kappa \mathrm{B}$ has been reported using DNA-based drugs, such as decoy oligonucleotides [24-27], as well as low molecular weight molecules $[28,29]$. However, NF- $\kappa$ B has also been reported as an antiapoptotic factor related to cell growth, suggesting that NF- $\kappa \mathrm{B}$ inhibitors (as found for TMA) might exhibit antiproliferative and/or cytotoxic effects.

In order to improve the anti-inflammatory activity of TMA and to reduce some related cytotoxic effects, we analyzed new thirty-eight TMA derivatives belonging to different chemical classes (series) and reported in Table 1, in order to verify whether compounds are present displaying effects on NF- $\kappa \mathrm{B}$, inflammatory-related proteins without major alteration of cell growth potential.

\section{Materials and Methods}

2.1. Synthesis and Characterization of TMA Analogues. TMA (4,6,4'-trimethylangelicin) was synthesized at the
Department of Pharmaceutical Sciences of the University of Padova [30], and it was dissolved in a mixture of methanol $(\mathrm{MeOH})$ and $3 \%$ of dimethyl sulfoxide (DMSO) to obtain the $10 \mathrm{mM}$ stock solution, stored at $-20^{\circ} \mathrm{C}$ in the dark. The working solutions were then obtained using $\mathrm{MeOH}$. TMA analogues were partly synthesized as previously described [31-40] and partly belong to the collection of the Organic Synthesis Lab (Dept. of Pharmaceutical Sciences, University of Padova). The stock solutions (100 mM) of each compound were prepared in DMSO and were diluted with $\mathrm{MeOH}$ to obtain the desired working solutions (10 mM-500 $\mu \mathrm{M})$, immediately before the in vitro experiments and treatment of cell cultures. No effect of the maximum concentrations employed on the vehicles on the test performed (cell growth, gene expression) was observed.

2.2. EMSA (Electrophoretic Mobility Shift Assays). Electrophoretic mobility shift assays were performed using double-stranded ${ }^{32} \mathrm{P}$-labeled oligonucleotides as target DNA. Binding reactions were set up as previously described [19] in binding buffer (10\% glycerol, 0.05\% NP-40, $10 \mathrm{mM}$ Tris- $\mathrm{HCl} \mathrm{pH} 7.5,50 \mathrm{mM} \mathrm{NaCl}, 0.5 \mathrm{mM}$ DTT, and $10 \mathrm{mM} \mathrm{MgCl} 2$ ), in the presence of $0.1 \mu \mathrm{l} / 20 \mu \mathrm{l}$ of NF- $\kappa$ B p50 (50 gsu) (Promega, Madison, WI, USA) and $0.25 \mathrm{ng}$ of labeled oligonucleotide, in a total volume of $20 \mu \mathrm{l}$. After $30 \mathrm{~min}$ binding at room temperature, samples were electrophoresed at constant voltage (200 V for $30 \mathrm{~min})$ through a low ionic strength (0.25 TBE buffer) (1 TBE/ 40.089 M Tris-borate, $0.002 \mathrm{M}$ EDTA) on $6 \%$ polyacrylamide gels until the tracking dye (bromophenol blue) reached the bottom of a $16 \mathrm{~cm}$ slab. Gels were dried and exposed for autoradiography with intensifying screens at $80^{\circ} \mathrm{C}$. In these experiments, DNA/protein complexes migrate through the gel with slower efficiency. In studies on the inhibitors of protein/DNA interactions, addition of the reagents was as follows: (i) nuclear factors, (ii) active principles, (iii) binding buffer, and (iv) labeled oligonucleotides mimicking the binding sites for TF to be modulated. The nucleotide sequence of double-stranded target DNA utilized in these experiments was 5'-CGC TGG GGA CTT TCC ACG G-3' (sense strand, $\mathrm{NF}-\kappa \mathrm{B})$. The synthetic oligonucleotides utilized in this study were purchased from Sigma Genosys (Sigma Genosys, Cambs, UK). To calculate the effective concentrations, three different autoradiograms obtained from different time exposures were scanned and compared to control EMSA performed without addition of angelicin analogues (two independent experiments were performed).

2.3. Cell Cultures. IB3-1 cells, derived from a CF patient with a $\triangle \mathrm{F} 508 / \mathrm{W} 1282 \mathrm{X}$ mutant genotype and immortalized with adeno12/SV40, were grown in LHC-8 supplemented with $5 \% \mathrm{FBS}$ in the absence of gentamycin, at $37^{\circ} \mathrm{C} / 5 \% \mathrm{CO}_{2}[12]$.

2.4. Cell Proliferation Assays. Monolayers of $60 \%$ confluent IB3-1 cells were seeded in 24- or 12-well plates in LHC-8 medium in the presence of 5\% FBS. After $24 \mathrm{~h}$, TMA derivatives were added at serial dilutions and incubated for further 2-3 days. The effects of compounds (TMA derivatives) on the cell proliferation were analyzed as elsewhere described. A 
TABLE 1: Chemical structure of lead compound 4,6, $4^{\prime}$-trimethylangelicin (TMA) and of TMA analogues.

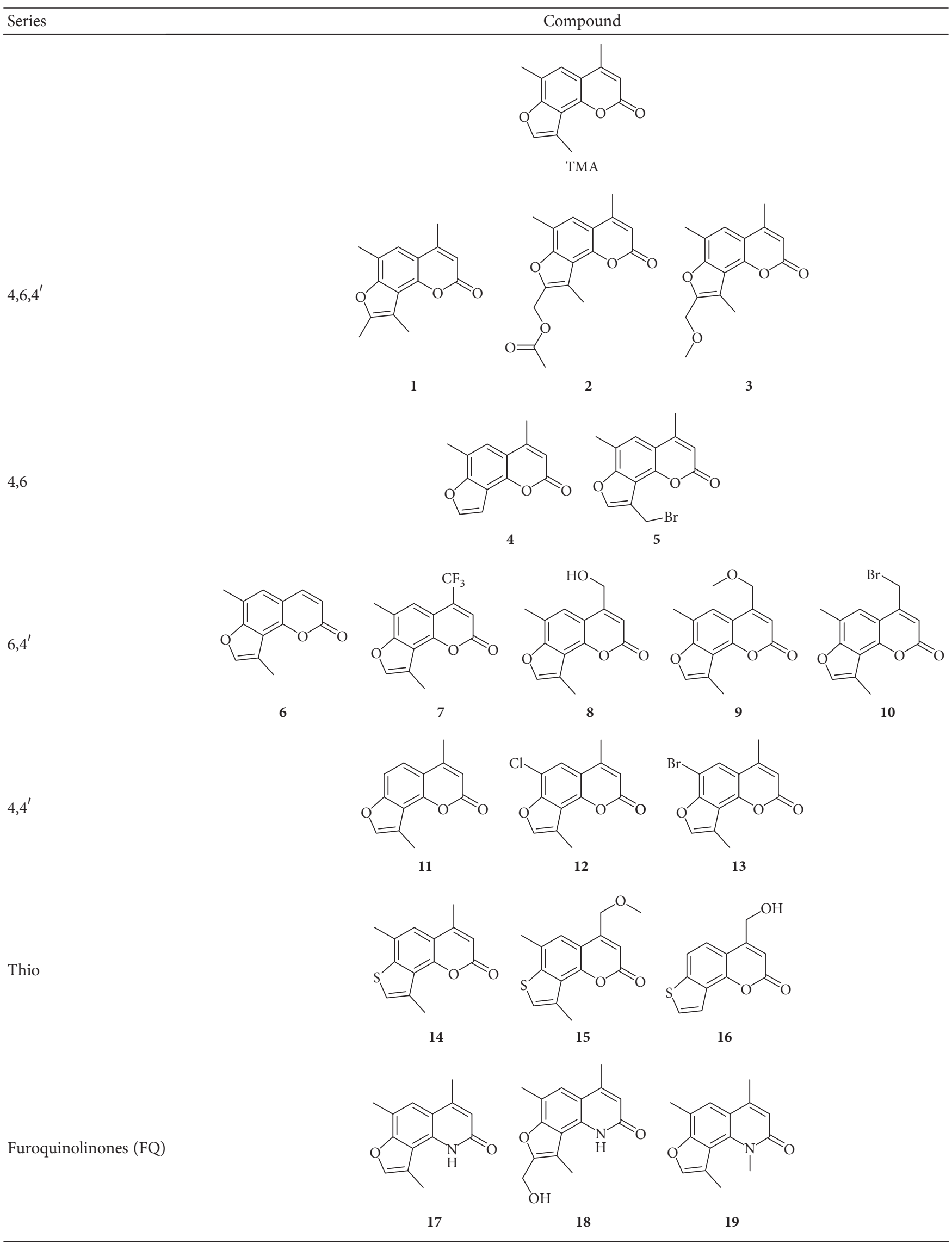


TABle 1: Continued.

Series

Compound

Dihydro<smiles>Cc1cc(=O)oc2c3c(ccc12)OC(C)C3</smiles>

20<smiles>COC1Cc2c(ccc3c(C)cc(=O)oc23)O1</smiles>

21<smiles>Cc1cc(=O)oc2c3c(ccc12)OC(CBr)C3</smiles>

22

Other angelicins<smiles>Cc1oc2c(C)cc3c(C)cc(=O)oc3c2c1CO</smiles>

23<smiles>Cc1cc2c(CO)cc(=O)oc2c2cc(CO)oc12</smiles>

24<smiles>Cc1cc2c(o1)c(C)cc1c(CO)cc(=O)oc12</smiles>

25<smiles>Cc1cc(=O)oc2c1ccc1oc(CN)cc12</smiles>

26

Chromone<smiles></smiles>

27

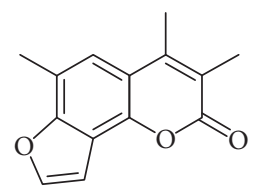

28

Difuro<smiles>Cc1coc2c1c1occ(C)c1c1oc(=O)cc(C)c21</smiles>

29<smiles>Cc1cc2c(o1)c1cc(C)oc1c1oc(=O)cc(C)c21</smiles>

30

Triazole<smiles>Cc1cc(=O)oc2c1cc(C)c1[nH]nnc12</smiles>

Allo

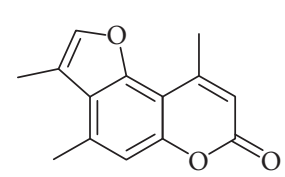

32<smiles>Cc1cc2c(C)cc3oc(=O)cc(C)c3c2o1</smiles>

33

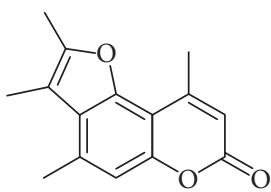

34 
TABle 1: Continued.

Coumarin

first analysis was performed with serial dilutions to obtain $50 \mu \mathrm{M}, 200 \mu \mathrm{M}$, and $800 \mu \mathrm{M}$ solutions. In order to determine $\mathrm{IC}_{50}$ values, the following concentrations were used 12.5, $25,50,100,200$, and $800 \mu \mathrm{M}$. In order to prepare the cells for counting, they were washed with PBS 1X and detached with trypsin/EDTA. Cells were suspended in physiological solution and counted with a Z2 Coulter Counter (Coulter Electronics, Hialeah, FL, USA). The cell number/ml was determined as $\mathrm{IC}_{50}$ after 2 days of culture, when untreated cells are in log phase of cell growth.

2.5. Quantification of $I L-8 \mathrm{mRNA}$ Content. Monolayers of $60 \%$ confluent IB3-1 cells were seeded in 6- or 12-well plates in LHC-8 medium in the presence of 5\% FBS. After $24 \mathrm{~h}$, pure derivatives were added, $5 \mathrm{~h}$ before stimulation with TNF- $\alpha 80 \mathrm{ng} / \mathrm{ml}$ (ORF Genetics, Kopavogur, Iceland), and incubated for a further $24 \mathrm{~h}$. Total RNA was extracted using TRIzol Reagent (Sigma-Aldrich, St. Louis, MO) following the manufacturer's instructions. Reverse transcription (RT) was performed using Reverse Transcription System kit (Promega, Madison, WI): $1 \mu \mathrm{g}$ of total RNA was reverse transcribed in the presence of $5 \mathrm{mM} \mathrm{MgCl}_{2}, 1 \mathrm{X}$ reverse transcription buffer $(10 \mathrm{mM}$ Tris- $\mathrm{HCl}, 50 \mathrm{mM} \mathrm{KCl}$, and $0.1 \%$ Triton X-100), $1 \mathrm{mM}$ each dNTPs, $20 \mathrm{U}$ recombinant Rnasin Ribonuclease Inhibitor, $15 \mathrm{U}$ AMV Reverse Transcriptase, and $0.5 \mu \mathrm{g}$ oligo(dT) 15 primers in a total volume of $20 \mu \mathrm{l}$ for $10 \mathrm{~min}$ at $70^{\circ} \mathrm{C}$ and $60 \mathrm{~min}$ at $42^{\circ} \mathrm{C}$. The resulting cDNA was quantified by relative quantitative real-time PCR (real-time qPCR). For real-time qPCR, $1 \mu \mathrm{l}$ of cDNA was used for each SYBR Green reaction to quantify the relative expression of IL-8. Each $25 \mu \mathrm{l}$ of total reaction volume contained $1 \mu \mathrm{l}$ of $\mathrm{cDNA}, 10 \mathrm{pmol}$ of primers, $1 \mathrm{iQTM}$ SYBR Green Supermix (Bio-Rad Laboratories Inc., Hercules, CA). Real-time PCRs were performed for a total of 40 cycles (denaturation, $95^{\circ} \mathrm{C}$ for $10 \mathrm{~s}$; annealing, $68^{\circ} \mathrm{C}$ for $30 \mathrm{~s}$ for $\mathrm{IL}-8, \quad 65^{\circ} \mathrm{C}$ for $30 \mathrm{~s}$ for IL-6; elongation, $72^{\circ} \mathrm{C}$ for $60 \mathrm{~s}$ ) using an iCycler IQ5 (Bio-Rad Laboratories Inc., Hercules, CA). Primer sequences were as follows: IL-8 forward:
5'-GTG CAG TTT TGC CAA GGA GT-3' and IL-8 reverse: 5'-TTA TGA ATT CTC AGC CCT CTT CAA AAA CTT CTC-3'. The relative proportions of each amplified template were determined utilizing the threshold cycle $\left(C_{T}\right)$ value for each performed PCR. The DDCt method was used to compare gene expression data. Each sample was quantified in duplicate. Changes in mRNA expression level were calculated following normalization with the GAPDH calibrator gene (housekeeping gene) and expressed as fold change over untreated samples [24]. Duplicates of negative controls (no template cDNA) were also run with every experimental plate to assess specificity and indicate potential contamination.

2.6. Bioplex Analysis. Cytokines, released from cells into tissue culture supernatants, were measured by Bioplex cytokine assay (Bio-Rad Laboratories Inc., Hercules, CA) as suggested by the manufacturer (Luminex technology) [41]. The Bioplex cytokine assay is designed for the multiplexed quantitative measurement of multiple cytokines in a single well using as little as $50 \mu$ l of sample. In our experiments, the premixed multiplex beads (27-plex) of the Bioplex human cytokines were used. $50 \mu \mathrm{l}$ of cytokine standards or samples (supernatants recovered from treated cells and diluted to $2 \mu \mathrm{g} / \mu \mathrm{l}$ ) were incubated with $50 \mu \mathrm{l}$ of anticytokine conjugated beads in 96-well filter plates for $30 \mathrm{~min}$ at room temperature with shaking. Plates were washed by vacuum filtration three times with $100 \mu \mathrm{l}$ of Bioplex wash buffer, $25 \mu \mathrm{l}$ of diluted detection antibody were added, and plates were incubated for $30 \mathrm{~min}$ at room temperature with shaking. After three filter washes, $50 \mu \mathrm{l}$ of streptavidin-phycoerythrin were added, and the plates were incubated for $10 \mathrm{~min}$ at room temperature with shaking. Finally, plates were washed by vacuum filtration three times, beads were suspended in Bioplex assay buffer, and samples were analyzed on a Bio-Rad 96-well plate reader using the Bioplex Suspension Array System and Bioplex Manager software (Bio-Rad Laboratories Inc., Hercules, CA). 


\section{Results}

3.1. Effects of TMA Derivatives on the In Vitro Proliferation of Cystic Fibrosis IB3-1 Cells. In order to obtain preliminary information on the biological properties of TMA derivatives, their effects on cell growth were examined on IB3-1 cell line, excellent biological model to study new potential antiinflammatory molecules. The use of this cell line to study the expression of proinflammatory molecules under a variety of stimuli is well established. Monolayers of $60 \%$ confluent IB3-1 cells were seeded in 12-well plate in LHC-8 medium with $5 \%$ FBS. After $24 \mathrm{~h}$, compounds were added at different concentrations and the cell number/ml was determined after further $48 \mathrm{~h}$ of culture. All the obtained $\mathrm{IC}_{50}$ values are reported in Table 2 .

Several TMA analogues displayed very low antiproliferative effects $(>800 \mu \mathrm{M})$, such as compounds $1-4,7,9,12-16$, $18,27-34,36$, and 37 . This lack of antiproliferative activity of these angelicin analogues was confirmed in further experiments, fully sustaining the conclusion that these analogues do not cause $50 \%$ inhibition of cell growth even when added at high concentration, being therefore of interest in the identification of possible inhibitors of inflammation-related genes without major toxic effects. TMA exhibited an $\mathrm{IC}_{50}$ value of $185 \pm 30 \mu \mathrm{M}$ (data not shown).

3.2. In Vitro Inhibition of $N F-\kappa B / D N A$ Interactions. The effects of TMA derivatives on NF- $\kappa \mathrm{B}$ - (nuclear factorkappaB-) mediated induction of proinflammatory genes was verified first in vitro by electrophoretic mobility shift assay (EMSA) with the aim to verify and quantify the possible inhibition of NF- $\kappa \mathrm{B} / \mathrm{DNA}$ interactions. This assay was performed using purified NF- $\kappa \mathrm{B}$ p50 and ${ }^{32} \mathrm{P}$-labeled target NF$\kappa \mathrm{B}$ double-stranded oligonucleotide mimicking the NF- $\kappa \mathrm{B}$ consensus sequence present within the IL- 8 gene promoter.

We first confirmed that TMA is able to suppress NF- $\kappa \mathrm{B}$ / DNA interactions when used at $100 \mu \mathrm{M}$ concentration (Figure 2); to verify whether new analogues were more active than the TMA lead compound, we performed an EMSAbased screening considering the TMA lowest active concentration to be higher than $20 \mu \mathrm{M}$ (Figure 2 and data not shown).

Preliminary data demonstrated that, when used at $100 \mu \mathrm{M}$ concentration, several derivatives fully suppress the interactions between NF- $\kappa \mathrm{B}$ p 50 and the target DNA, while other molecules (compounds 2, 3, 6, 7, 11, 14, 15, 17, 22, and 24) were not analyzed because the relative EMSA experiments demonstrated low activity $(\mathrm{MIC}>100 \mu \mathrm{M})$ (data not shown). According to these first results, further analyses were performed using different dilutions of the selected active compounds, exhibiting MIC values ranging from $12.5 \mu \mathrm{M}$ to $100 \mu \mathrm{M}$, as represented in Figures 3 and 4 and summarized in Table 3, reporting their MIC values.

Among the "4,6,4' series" (compounds 1, 2, and 3), the most interesting molecule was compound $\mathbf{1}$, showing MIC $<12.5 \mu \mathrm{M}$, while 4 and 5 derivatives, belonging to the " 4,6 series" were active at $75 \mu \mathrm{M}$ and $25 \mu \mathrm{M}$, respectively.

The " $6,4^{\prime}$ series," including $\mathbf{8}, \mathbf{9}$, and $\mathbf{1 0}$ analogues, displayed excellent inhibitory activities $(35 \mu \mathrm{M}, 12.5 \mu \mathrm{M}$, and $<12.5 \mu \mathrm{M}$ MIC, resp.).
TABLE 2: $\mathrm{IC}_{50}$ values calculated after $48 \mathrm{~h}$ from treatment of IB3-1 cells with serial dilutions of TMA derivatives.

\begin{tabular}{|c|c|}
\hline Derivative & $\mathrm{IC}_{50}(48 \mathrm{~h})$ \\
\hline 1 & $>800 \mu \mathrm{M}$ \\
\hline 2 & $>800 \mu \mathrm{M}$ \\
\hline 3 & $>800 \mu \mathrm{M}$ \\
\hline 4 & $>800 \mu \mathrm{M}$ \\
\hline 5 & $485.89 \mu \mathrm{M}$ \\
\hline 6 & $454.35 \mu \mathrm{M}$ \\
\hline 7 & $>800 \mu \mathrm{M}$ \\
\hline 8 & $397.87 \mu \mathrm{M}$ \\
\hline 9 & $>800 \mu \mathrm{M}$ \\
\hline 10 & $<50 \mu \mathrm{M}$ \\
\hline 11 & $181.78 \mu \mathrm{M}$ \\
\hline 12 & $>800 \mu \mathrm{M}$ \\
\hline 13 & $>800 \mu \mathrm{M}$ \\
\hline 14 & $>800 \mu \mathrm{M}$ \\
\hline 15 & $>800 \mu \mathrm{M}$ \\
\hline 16 & $>800 \mu \mathrm{M}$ \\
\hline 17 & $193.07 \mu \mathrm{M}$ \\
\hline 18 & $>800 \mu \mathrm{M}$ \\
\hline 19 & $131.12 \mu \mathrm{M}$ \\
\hline 20 & $154.43 \mu \mathrm{M}$ \\
\hline 21 & $677.87 \mu \mathrm{M}$ \\
\hline 22 & $179.92 \mu \mathrm{M}$ \\
\hline 23 & $451.66 \mu \mathrm{M}$ \\
\hline 24 & $196.53 \mu \mathrm{M}$ \\
\hline 25 & $551.23 \mu \mathrm{M}$ \\
\hline 26 & $90.84 \mu \mathrm{M}$ \\
\hline 27 & $>800 \mu \mathrm{M}$ \\
\hline 28 & $>800 \mu \mathrm{M}$ \\
\hline 29 & $>800 \mu \mathrm{M}$ \\
\hline 30 & $>800 \mu \mathrm{M}$ \\
\hline 31 & $>800 \mu \mathrm{M}$ \\
\hline 32 & $>800 \mu \mathrm{M}$ \\
\hline 33 & $>800 \mu \mathrm{M}$ \\
\hline 34 & $>800 \mu \mathrm{M}$ \\
\hline 35 & $137.31 \mu \mathrm{M}$ \\
\hline 36 & $>800 \mu \mathrm{M}$ \\
\hline 37 & $>800 \mu \mathrm{M}$ \\
\hline 38 & $505.81 \mu \mathrm{M}$ \\
\hline
\end{tabular}

In the same figure, we may also observe high activity of $\mathbf{1 2}$ and 13 derivatives (" $4,4^{\prime}$ series") showing low MIC value $(12.5 \mu \mathrm{M})$, while among the "thio-series" $(\mathbf{1 4}, \mathbf{1 5}$, and 16), only 16 demonstrated a $50 \mu \mathrm{M}$ MIC value. All furoquinolinone analogues, belonging to the "FQ series" $(\mathbf{1 7}, \mathbf{1 8}$, and 19), were considered inactive when compared with TMA (MIC > $100 \mu \mathrm{M})$.

Among derivatives belonging to "other angelicins" group, compounds 23, 25, and 26 were able to inhibit the NF- $\kappa \mathrm{B} /$ DNA interaction showing MIC values of $25-50 \mu \mathrm{M}$. 


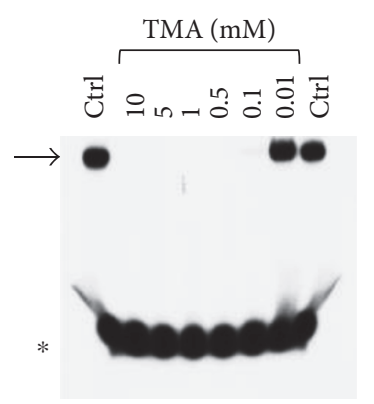

Figure 2: Effects of TMA on the molecular interactions between NF- $\kappa$ B p50 and a ${ }^{32}$ P-labeled target NF- $\kappa$ B double-stranded oligonucleotide. TMA was first incubated with NF- $\kappa \mathrm{B}$, and then the ${ }^{32}$ P-labeled target NF- $\kappa$ B oligonucleotide was added. NF- $\kappa \mathrm{B} / \mathrm{DNA}$ complexes were analyzed by polyacrylamide gel electrophoresis. Arrow indicates NF- $\kappa \mathrm{B} / \mathrm{DNA}$ complexes; asterisk indicates the free ${ }^{32} \mathrm{P}$-labeled target NF- $\kappa \mathrm{B}$ probe.

All the derivatives starting from 27 to $\mathbf{3 8}$ showed interesting MIC values in EMSA (Figure 4). Indeed, we observed a MIC value $<12.5 \mu \mathrm{M}$ for the chromone derivative 27. The 3,4 analogue 28 inhibits the NF- $\kappa \mathrm{B} / \mathrm{DNA}$ interaction at $15 \mu \mathrm{M}$.

Among "difuro series," we observed a MIC value < $12.5 \mu \mathrm{M}$ when 29 is added to binding reaction, and we observed an MIC value of $15 \mu \mathrm{M}$ for derivative $\mathbf{3 0}$.

Triazole analogue 31 demonstrated its activity at $25 \mu \mathrm{M}$.

Among "allo series," two TMA isosters, 32 and 33, showed MIC values of $12.5 \mu \mathrm{M}$ and $15 \mu \mathrm{M}$, respectively.

Among "pyran series," compound 36 demonstrated the most interesting inhibitory effect showing $15 \mu \mathrm{M}$ MIC value; derivative 35 was able to interfere with the NF- $\kappa \mathrm{B} / \mathrm{DNA}$ interaction at $35 \mu \mathrm{M}$ MIC. Finally, two coumarin compounds, 37 and 38, both exhibited active at $25 \mu \mathrm{M}$ MIC.

In conclusion, several TMA derivatives were found to be more active than the reference compound TMA, such as $\mathbf{1 , 5}$, $10,12,23,27-29,31,32,34$, and 36-38.

3.3. Inhibition of IL-8 mRNA Accumulation in TNF- $\alpha$ Treated IB3-1 Cystic Fibrosis Cells. With the aim to study the effective anti-inflammatory properties of these new psoralen derivatives, we decided to further characterize the TMA derivatives for their potential activities on the expression of IL-8 gene, known to be involved in the lung inflammatory process in CF. It is firmly established that IL-8 gene expression is regulated at least in part by the NF- $\kappa \mathrm{B}$ transcription factor [24-26]; therefore, since molecules inhibiting $\mathrm{NF}-\kappa \mathrm{B} / \mathrm{DNA}$ interactions might exhibit inhibitory activities on $\mathrm{NF}-\kappa \mathrm{B}$-regulated genes [27], we were interested in determining the activity of TMA analogues on IL-8 gene expression. More specifically, we were first interested in identifying compounds with low antiproliferative activity, but effective in downmodulating inflammatory gene expression without achieving a full suppression of these genes. We therefore employed IB3-1 cystic fibrosis cells, incubated for $5 \mathrm{~h}$ with two concentrations $(1 \mu \mathrm{M}$ and $10 \mu \mathrm{M})$ of selected compounds, and then treated with TNF- $\alpha(100 \mu \mathrm{g} / \mathrm{ml})$. In the IB3-1 cystic fibrosis cellular model, NF- $\kappa$ B-dependent genes, including the gene encoding for the proinflammatory protein IL-8, generally are activated following infection with $P$. aeruginosa or treatment with TNF- $\alpha$ or IL- $1 \beta[26,28,31]$. This feature is very important in the pathophysiology of CF, since several clinical complications are caused by exacerbation of this inflammatory response. After 1 day of incubation, cellular RNA was isolated for RT-qPCR analysis. All the TMA analogues found to be active in inhibiting NF- $\kappa \mathrm{B} /$ DNA interactions were analyzed for their effects on inhibition of TNF- $\alpha$-induced accumulation of IL- 8 mRNA.

The results of RT-qPCR analyses obtained are summarized in Table 3. Our results demonstrated that treatment of IB3-1 cells with TNF- $\alpha$ induces a fast and sharp IL- 8 gene overexpression. This effect is clearly inhibited by the presence of some TMA derivatives, the most active being $\mathbf{1 , ~ 8 , ~ 2 6 , ~ 3 2 , ~}$ $33,34,36$, and 38 .

3.4. Bioplex Analysis. In order to verify the effects on the secretion of IL- 8 by IB3-1 cells, Luminex technology was employed to detect and quantify proteins secreted into the medium. This proof-of-principle was conducted on compound 1 since using high concentrations of this compound, no antiproliferative activity was observed $\left(\mathrm{IC}_{50}>800 \mu \mathrm{M}\right)$, despite the fact that this compound was one of the most active in inhibiting NF- $\kappa \mathrm{B} / \mathrm{DNA}$ interactions (see Figure 3 ). The found results were in full agreement with those obtained studying IL-8 mRNA accumulation, showing that the inhibition of IL- 8 is higher than that induced by TMA. This is shown in Figure 5, which supports the decrease of IL-8 expression during treatment with derivative $1(1 \mu \mathrm{M})$, showing about $50 \%$ reduction of IL- 8 secretion when compared to untreated, TNF- $\alpha$-stimulated cells. This effect was higher than $1 \mu \mathrm{M}$ TMA and similar to that found with $10 \mu \mathrm{M}$ TMA. The higher efficiency of compound 1 with respect to TMA was reproducibly observed in three independent experiments. As far as the other cytokines, chemokines, and growth factors that can be analyzed with the Bioplex approach, only minor (less than $10 \%$ variation) effects were found for all the secreted proteins analyzed with the exception of the TNF- $\alpha$-inducible IP-10, which was further increased (more than twofold in three independent experiments). Altogether, these data suggest that compound $\mathbf{1}$ is a very interesting inhibitor of proinflammatory cytokine's activities.

\section{Discussion}

Psoralens are well-known furocoumarins belonging to the class of photosensitizers used for their activity in the treatment of various chronic inflammatory skin diseases, and they are characterized by a differently substituted tricyclic aromatic skeleton, derived from condensation of a coumarin nucleus with a furan ring. Among psoralen-related compounds, the angular angelicin- (ANG-) like isomers are both synthetic and natural compounds that we demonstrated exhibiting interesting pharmacological activities compared with linear psoralens [11].

Recently, we established that 4,6,4'-trimethylangelicin (TMA) is a strong inhibitor of the expression of the IL-8 gene in bronchial epithelial cells in which the inflammatory 

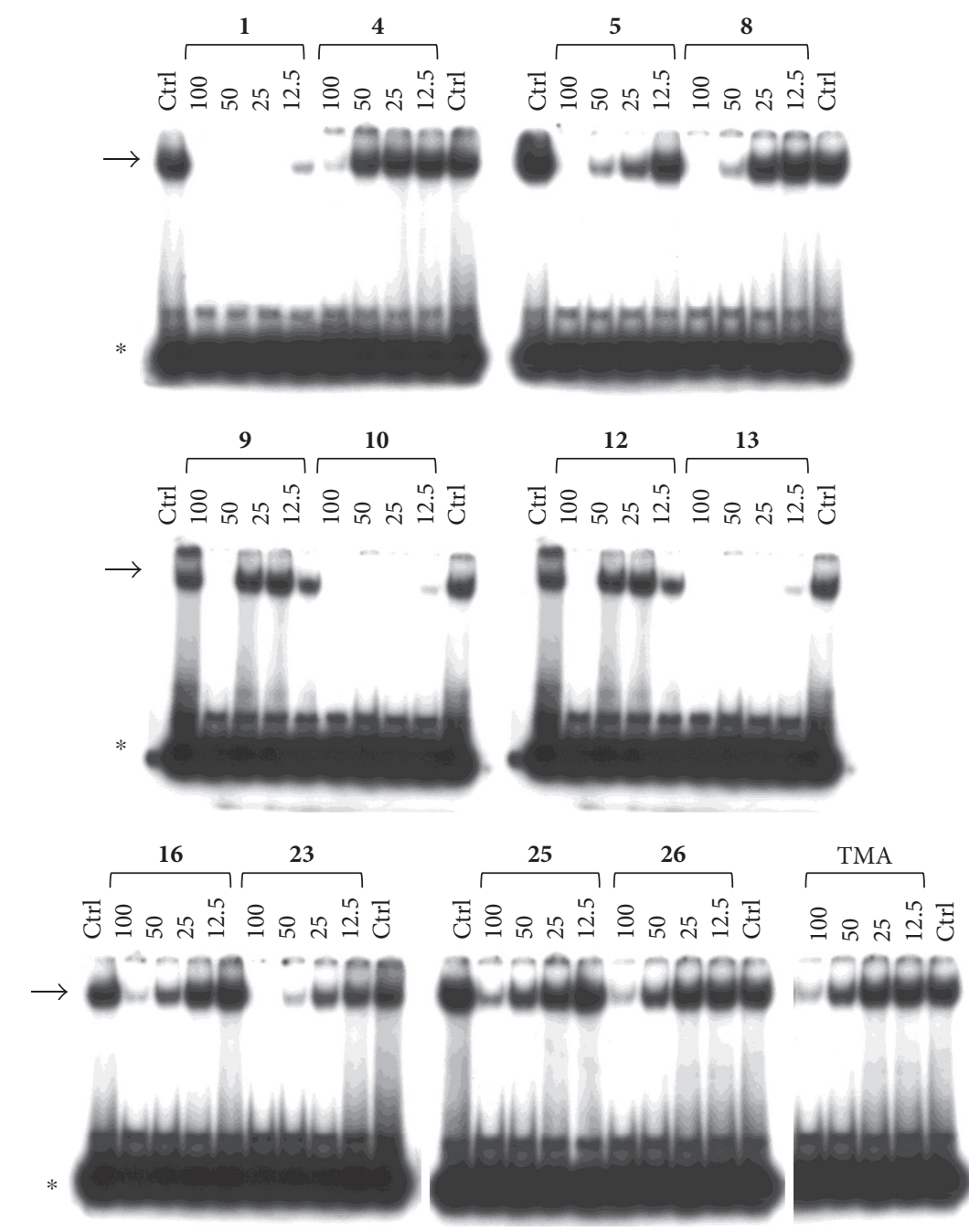

FIGURE 3: Representative results depicting the effects of TMA analogues (1-26) at 12.5-100 $\mu \mathrm{M}$ concentrations, compared to TMA in EMSA experiments on the molecular interactions between $\mathrm{NF}-\kappa \mathrm{B}$ p50 and ${ }^{32} \mathrm{P}$-labeled target NF- $\kappa \mathrm{B}$ double-stranded oligonucleotide. Compounds $2,3,6,7,11,14,15,17-22$, and 24 were not analyzed because the relative EMSA experiments demonstrated low activity $(\mathrm{MIC}>100 \mu \mathrm{M})$. Arrow indicates NF- $\kappa \mathrm{B} / \mathrm{DNA}$ complexes; asterisk indicates the free ${ }^{32} \mathrm{P}$-labeled target NF- $\kappa \mathrm{B}$ probe.

response has been challenged with $P$. aeruginosa [12], the most common bacterium found in the airways of patients affected by cystic fibrosis (CF). These findings suggested us to continue our research analyzing 38 new analogues of TMA in order to evaluate their biological activities on human bronchial epithelial cells IB3-1, derived from a CF patient with a $\Delta \mathrm{F}-508 / \mathrm{W} 1282 \mathrm{X}$ mutant genotype. This cellular system is very attractive, since it is well known that the hallmark in CF airway pathology is a characteristic elevated concentration of proinflammatory cytokines and chemokines, the most important of which seems to be IL-8.

In the field of research about $\mathrm{CF}$, the study of novel and innovative drugs for the treatment of this pathology is constantly evolving in order to ameliorate the clinical conditions of patients. In the conventional treatment of $\mathrm{CF}$, the commonly utilized drugs are nonsteroidal anti-inflammatory drugs (NSAIDs) and steroid derivatives that possess, in addition to great benefits, many known side effects. The search for modern therapies to counteract the inflammation in CF patients is aimed at finding new potential antiinflammatory drugs with alternative mechanisms of action that may replace the use of typical drugs.

In inflammatory processes that involve patients with $\mathrm{CF}$, $\mathrm{NF}-\kappa \mathrm{B}$ transcription factor plays a crucial role. Indeed, the expression of many genes encoding for cytokines, chemokines, adhesion molecules, and other proteins involved in inflammation is regulated by NF- $\kappa \mathrm{B}$. The NF- $\kappa \mathrm{B}$ dimers, as the predominant $\mathrm{p} 50 / \mathrm{p} 65$ heterodimer, following a cascade of intracellular biochemical events activated by extracellular stimuli including cytokines as TNF-alpha (TNF- $\alpha$ ), are left free to move into the nucleus, where they activate specific proinflammatory genes. For this reason, it is extremely interesting to find new potential anti-inflammatory drugs, which inhibit the action of NF- $\kappa \mathrm{B}$ and the subsequent production of cytokines (particularly IL-8). 


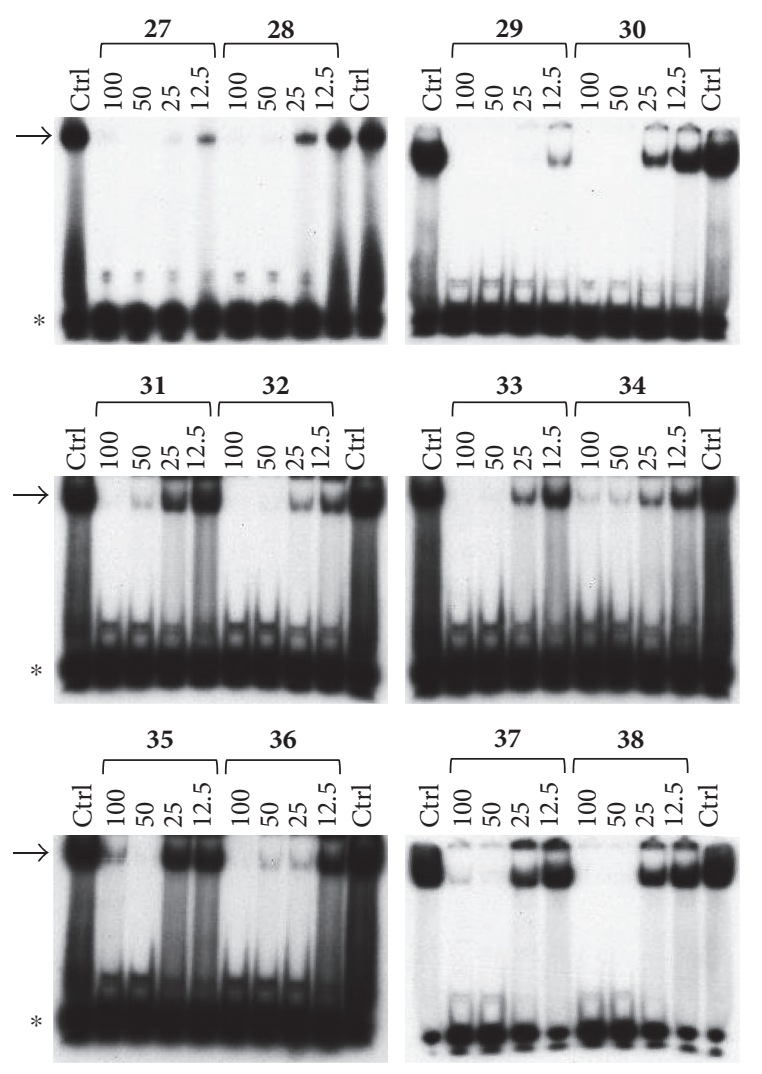

FIGURE 4: Representative results depicting the effects of TMA analogues (27-38) at $12.5-100 \mu \mathrm{M}$ concentrations, compared to TMA in EMSA experiments on the molecular interactions between NF- $\kappa$ B p50 and ${ }^{32}$ P-labeled target NF- $\kappa$ B double-stranded oligonucleotide. Arrow indicates NF- $\kappa \mathrm{B} / \mathrm{DNA}$ complexes; asterisk indicates the free ${ }^{32} \mathrm{P}$-labeled target NF- $\kappa \mathrm{B}$ probe.

Because our previous studies demonstrated that TMA inhibits NF- $\kappa \mathrm{B} / \mathrm{DNA}$ interactions in vitro in EMSA experiments at $100 \mu \mathrm{M}$ concentration [12], band shift analyses were performed to find new derivatives able to inhibit the interaction between purified p50 subunit of NF- $\kappa \mathrm{B}$ and DNA-specific target mimicking IL-8 promoter. Considering these preliminary results, new TMA derivatives able to inhibit NF- $\kappa \mathrm{B} / \mathrm{DNA}$ interaction at lower concentration than lead compound TMA were selected to investigate their biological activity on IB3-1 cells induced with TNF- $\alpha$. In this system, NF- $\kappa \mathrm{B}$-dependent genes, including those encoding for the proinflammatory protein IL-8, were investigated. TNF- $\alpha$-induced expression of IL- 8 was evaluated by quantitative reverse transcription and polymerase chain reaction (RT-qPCR) in IB3-1 cells incubated with $1 \mu \mathrm{M}$ and $10 \mu \mathrm{M}$ of active compounds. All the obtained results are summarized in Table 3.

The most interesting compounds showing relevant antiinflammatory effects are compounds $1,32,33,34$, and 36 derivatives. As expected by EMSA results, these proralens were able to reduce IL-8 mRNA expression of $57 \%(1 \mu \mathrm{M})$, $73 \%(1 \mu \mathrm{M}), 66 \%(1 \mu \mathrm{M}), 68 \%(1 \mu \mathrm{M})$, and $77 \%(1 \mu \mathrm{M})$, respectively, without antiproliferative effects at the used concentrations $\left(\mathrm{IC}_{50}>800 \mathrm{mM}\right)$. Biological activities of all
TABLE 3: Results of RT-qPCR analysis reporting the \% inhibition of IL- 8 mRNA in TNF- $\alpha$-induced IB3- 1 cells cultured with $1 \mu \mathrm{M}$ and $10 \mu \mathrm{M}$ concentrations of TMA derivatives.

\begin{tabular}{|c|c|c|c|}
\hline Derivative & $\begin{array}{c}1 \mu \mathrm{M} \\
\text { (\% inhibition) }\end{array}$ & $\begin{array}{c}10 \mu \mathrm{M} \\
\text { (\% inhibition) }\end{array}$ & $\begin{array}{c}\text { Inhibition of } \\
\text { NF- } \kappa \mathrm{B} / \mathrm{DNA} \\
\text { complex (MIC) } \mu \mathrm{M}\end{array}$ \\
\hline 1 & 57 & 56 & $<12.5\left(^{*}\right)$ \\
\hline 5 & 33 & 31 & $12.5-25$ \\
\hline 8 & 51 & 52 & $25-50$ \\
\hline 12 & 0 & na & 12.5 \\
\hline 16 & 18 & 21 & $25-50$ \\
\hline 23 & 3 & 11 & $2-505$ \\
\hline 25 & na & na & $50-100$ \\
\hline 26 & 55 & 83 & $50-100$ \\
\hline 27 & 16 & na & $<12.5\left(^{*}\right)$ \\
\hline 28 & 21 & 36 & $12.5-25$ \\
\hline 29 & na & 12 & $<12.5\left(^{*}\right)$ \\
\hline 30 & 10 & na & $12.5-25$ \\
\hline 31 & na & na & 12.5 \\
\hline 32 & 73 & 52 & $<12.5\left(^{*}\right)$ \\
\hline 33 & 68 & 67 & $12.5-25$ \\
\hline 34 & 66 & 47 & $<12.5\left(^{*}\right)$ \\
\hline 35 & 56 & 37 & $25-50$ \\
\hline 36 & 77 & 74 & $12.5-25$ \\
\hline 37 & na & na & $12.5-25$ \\
\hline 38 & 36 & 81 & 25 \\
\hline
\end{tabular}

na: not active at the used concentrations; MIC: minimal inhibitory concentration. ${ }^{*}$ In the EMSA experiments, $12.5 \mu \mathrm{M}$ was the minor concentration used.

TNF- $\alpha$

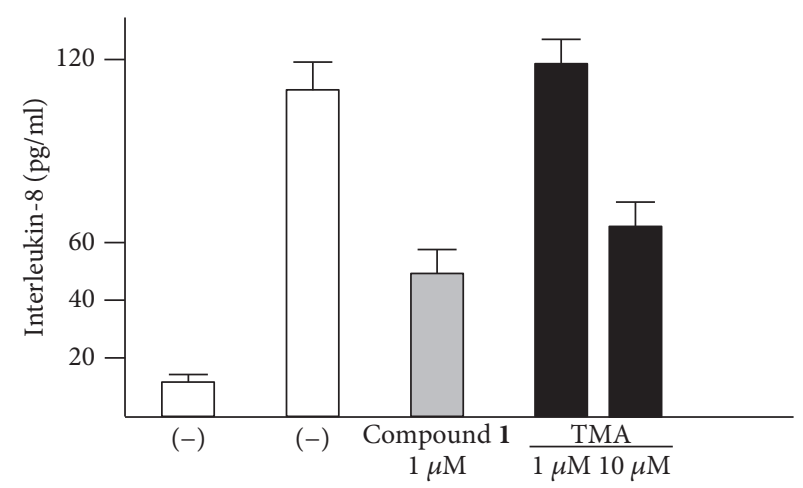

FIGURE 5: Bioplex analysis of IL-8 release (pg/ml) in IB3-1 cells induced with TNF- $\alpha$ in the absence and in the presence of compound $1(1 \mu \mathrm{M})$; the effects of $1 \mu \mathrm{M}$ and $10 \mu \mathrm{M}$ TMA were included for comparison $(n=3)$. IB3-1 cells were treated with compound 1 for 5 hours and then stimulated with TNF- $\alpha$ for further 24 hours. The supernatants were analyzed using a Bioplex cytokine assay.

the analyzed TMA derivatives were observed at low concentrations $(1-10 \mu \mathrm{M})$, without changes in cell proliferation. Other TMA analogues $(\mathbf{8}, \mathbf{2 6}, \mathbf{3 3}$, and 38$)$ showed high 
inhibitory effects (52-83\%) on IL-8 expression in IB3-1 cell model, demonstrating their potential power in a possible anti-inflammatory therapy, together with $\mathbf{2 6}, \mathbf{3 8}, \mathbf{3 6}$, and 32 .

Some analogues, finally, including $\mathbf{2}, 5,7$, and $\mathbf{2 8}$, showed similar activity (33-38\% of inhibition of IL-8 expression) to the lead compound TMA, even though they were considered not promising in EMSA assay.

The biological data allow to determine a very preliminary SAR (structure-activity relationship). Almost all the active compounds possess a tricyclic backbone with furocoumarin structures. The heteroatoms in the policyclic skeleton must be oxygen atoms, since all isosteric substitutions led to poorly active or inactive compounds ("thio series" 14-18, "FQ series" 17-19, and "triazole series" 31 ).

The steric hindrance of the substituent in the furocoumarin skeleton appears detrimental for the activity, since almost all the active compounds are methyl derivatives. Monohydroxymethyl derivatives or monoaminomethyl compounds are still active $(\mathbf{8}, \mathbf{2 6}$, and $\mathbf{3 8})$, but more hindered compounds are inactive.

The furan ring can be condensed at the 5,6 positions of the central benzene ring ("allo series" 32-34) as well as at the 7,8 positions $(\mathbf{1}, \mathbf{5}, \mathbf{8}, \mathbf{2 6}$, and $\mathbf{2 8})$, without impairing the activity, but not at both the positions at the same time ("difuro series" 29-30). The furan ring can be replaced by a pyran one maintaining a good inhibition of IL-8 expression ("pyran series" 35-36). Moreover, the furan ring must be fully aromatic, since the hydrogenated derivatives are inactive ("dihydro series" 20-22).

The coumarin moiety must be in the $\alpha$-pyron conformation since other structural disposition ( $\gamma$-pyron) affords inactive product ("chromone series" 27).

Finally, the tricyclic derivatives appear to be the more promising ones: the bicyclic derivatives are active only if a substituent mimicking the furan shape is present at the 8 positions ("coumarin series" 38).

\section{Conclusions}

Our data conclusively allowed the identification of novel TMA analogues exhibiting improved inhibitory activity on NF- $\kappa \mathrm{B} / \mathrm{DNA}$ interactions, IL-8 gene expression with only minor effects on cell growth. Although epithelial cells lying the surface of the airway tract are considered good sensors of the activity of promising anti-inflammatory agents, the effect of the most interesting TMA derivatives should be in the future extended also to the whole lung tissues of mice infected in vivo, in order to verify the possibility of multiple anti-inflammatory effects on different cells orchestrating the innate immune response in the lung.

\section{Conflicts of Interest}

The authors declare that there is no conflict of interest regarding the publication of this paper.

\section{Acknowledgments}

This study was supported by FFC (Fondazione Ricerca Fibrosi Cistica) Projects FFC\#1/2016 (Adriana Chilin) and FFC\#3/2016 (Roberto Gambari) and CIB (Consorzio Interuniversitario di Biotecnologie).

\section{References}

[1] T. B. Fitzpatrick and M. A. Pathak, "Part IV: basic considerations of the psoralens: historical aspects of methoxsalen and other furocoumarins 11 from the Division of Dermatology, University of Oregon Medical School, Portland, Oregon," Journal of Investigative Dermatology, vol. 32, no. 2, pp. 229231, 1959.

[2] M. R. Hamblin and Y.-Y. Huang, Handbook of Photomedicine, CRC Press, 2013.

[3] L. Santana, E. Uriarte, F. Roleira, N. Milhazes, and F. Borges, "Furocoumarins in medicinal chemistry. Synthesis, natural occurrence and biological activity," Current Medicinal Chemistry, vol. 11, no. 24, pp. 3239-3261, 2004.

[4] M. Berenbaum, J. Nitao, and A. Zangerl, "Adaptive significance of furanocoumarin diversity in Pastinaca sativa (Apiaceae)," Journal of Chemical Ecology, vol. 17, no. 1, pp. 207-215, 1991.

[5] F. Bourgaud, A. Gravot, S. Milesi, and E. Gontier, "Production of plant secondary metabolites: a historical perspective," Plant Science, vol. 161, no. 5, pp. 839-851, 2001.

[6] F. Dall'Acqua, G. Viola, and D. Vedaldi, Cellular and Molecular Target of Psoralen. In CRC Handbook of Organic Photochemistry and Photobiology, W. M. Hoorspool and F. Lenci, Eds., CRC Press, Boca Raton, FL, 2004.

[7] A. Guerrini, I. Lampronti, N. Bianchi et al., "Bergamot (Citrus bergamia Risso) fruit extracts as $\gamma$-globin gene expression inducers: phytochemical and functional perspectives," Journal of Agricultural and Food Chemistry, vol. 57, no. 10, pp. 41034111, 2009.

[8] A. Taieb, A. Alomar, M. Bohm et al., "Guidelines for the management of vitiligo: the European Dermatology Forum consensus," British Journal of Pharmacology, vol. 168, no. 1, pp. 1365-2133, 2012.

[9] J. A. Parrish, T. B. Fitzpatrick, L. Tanenbaum, and M. A. Pathak, "Photochemotherapy of psoriasis with oral methoxsalen and long wave ultraviolet light," The New England Journal of Medicine, vol. 291, no. 23, pp. 1207-1212, 1974.

[10] I. Lampronti, D. Martello, N. Bianchi et al., "In vitro antiproliferative effects on human tumor cell lines of extracts from the Bangladeshi medicinal plant Aegle marmelos Correa," Phytomedicine, vol. 10, no. 4, pp. 300-308, 2003.

[11] I. Lampronti, N. Bianchi, M. Borgatti, E. Fibach, E. Prus, and R. Gambari, "Accumulation of gamma-globin mRNA in human erythroid cells treated with angelicin," European Journal of Haematology, vol. 7, no. 3, pp. 189-195, 2003.

[12] A. Tamanini, M. Borgatti, A. Finotti et al., "Trimethylangelicin reduces IL-8 transcription and potentiates CFTR function," American Journal of Physiology - Lung Cellular and Molecular Physiology, vol. 300, no. 3, pp. 380-390, 2011.

[13] M. Favia, M. T. Mancini, V. Bezzerri et al., "Trimethylangelicin promotes the functional rescue of mutant F508del CFTR protein in cystic fibrosis airway cells," American Journal of Physiology - Lung Cellular and Molecular Physiology, vol. 307 , no. 1, pp. 48-61, 2014. 
[14] F. S. Collins, "Cystic fibrosis: molecular biology and therapeutic implications," Science, vol. 256, no. 5058, pp. 774779, 1983.

[15] K. Zerres, M. C. Volpen, and H. Weiss, "Cystic kidneys. Genetics, pathologic anatomy, clinical picture, and prenatal diagnosis," Human Genetics, vol. 68, no. 2, pp. 104-135, 1984.

[16] J. R. Riordan and X. B. Chang, "CFTR, a channel with the structure of a transporter," Biochimica et Biophysica Acta (BBA), vol. 1101, no. 2, pp. 221-222, 1992.

[17] J. M. Pilewski and R. A. Frizzell, "Role of CFTR in airway disease," Physiological Reviews, vol. 79, Supplement 1, pp. 215-255, 1999.

[18] J. S. Elborn, "Cystic fibrosis," Lancet, vol. 388, no. 10059, pp. 2519-2531, 2016.

[19] D. P. Nichols and J. F. Chmiel, "Inflammation and its genesis in cystic fibrosis," Pediatric Pulmonology, vol. 50, Supplement 40, pp. S39-S56, 2015.

[20] A. M. Cantin, D. Hartl, M. W. Konstan, and J. F. Chmiel, "Inflammation in cystic fibrosis lung disease: pathogenesis and therapy," Journal of Cystic Fibrosis, vol. 14, no. 4, pp. 419-430, 2015.

[21] A. R. Turnbull and J. C. Davies, "New drug developments in the management of cystic fibrosis lung disease," Expert Opinion on Pharmacotherapy, vol. 17, no. 8, pp. 1103-1112, 2016.

[22] S. Luqman and J. M. Pezzuto, "NF $\kappa$ B: a promising target for natural products in cancer chemoprevention," Phytotherapy Research, vol. 24, no. 7, pp. 949-963, 2010.

[23] G. Sethi, B. Sung, and B. Aggarwal, "Nuclear factor- $\kappa$ B activation: from bench to bedside," Experimental Biology and Medicine, vol. 233, no. 1, pp. 21-31, 2008.

[24] V. Bezzerri, M. Borgatti, E. Nicolis et al., "Transcription factor oligodeoxynucleotides to NF-kappaB inhibit transcription of IL-8 in bronchial cells," American Journal of Respiratory Cell and Molecular Biology, vol. 39, no. 1, pp. 86-96, 2008.

[25] V. Bezzerri, M. Borgatti, A. Finotti, A. Tamanini, R. Gambari, and G. Cabrini, "Mapping the transcriptional machinery of the IL-8 gene in human bronchial epithelial cells," Journal of Immunology, vol. 187, no. 11, pp. 6069-6081, 2011.

[26] P. R. Wardwell and R. A. Bader, "Immunomodulation of cystic fibrosis epithelial cells via NF- $\kappa$ B decoy oligonucleotide-coated polysaccharide nanoparticles," Journal of Biomedical Materials Research Part A, vol. 103, no. 5, pp. 1622-1631, 2015.

[27] D. De Stefano, G. De Rosa, and R. Carnuccio, "NF- $\kappa$ B decoy oligonucleotides," Current Opinion in Molecular Therapeutics, vol. 12, no. 2, pp. 203-213, 2010.

[28] M. Borgatti, A. Chilin, L. Piccagli et al., "Development of a novel furocoumarin derivative inhibiting NF- $\kappa$ B dependent biological functions: design, synthesis and biological effects," European Journal of Medicinal Chemistry, vol. 46, no. 10, pp. 4870-4877, 2011.

[29] G. Marzaro, A. Guiotto, M. Borgatti et al., "Psoralen derivatives as inhibitors of NF- $\kappa \mathrm{B} / \mathrm{DNA}$ interaction: synthesis, molecular modeling, 3D-QSAR, and biological evaluation," Journal of Medicinal Chemistry, vol. 56, no. 5, pp. 18301842, 2013.

[30] A. Guiotto, P. Rodighiero, and P. Manzini, "6-Methylangelicins: a new series of potential photochemotherapeutic agents for the treatment of psoriasis," Journal of Medicinal Chemistry, vol. 27, no. 8, pp. 959-967, 1984.

[31] F. Dall'Acqua, D. Vedaldi, A. Guiotto et al., "Methylangelicins: new potential agents for the photochemotherapy of psoriasis.
Structure-activity study on the dark and photochemical interactions with DNA," Journal of Medicinal Chemistry, vol. 24, no. 7, pp. 806-811, 1981.

[32] F. Dall'Acqua, D. Vedaldi, F. Bordin et al., " 4 '-Methylangelicins: new potential agents for the photochemotherapy of psoriasis," Journal of Medicinal Chemistry, vol. 26, no. 6, pp. 870-876, 1983.

[33] F. Bordin, F. Dall'Acqua, and A. Guiotto, “Angelicins, angular analogs of psoralens: chemistry, photochemical, photobiological and phototherapeutic properties," Pharmacology \& Therapeutics, vol. 52, no. 3, pp. 331-363, 1991.

[34] M. Amelia, L. Tarpani, L. Latterini et al., "Photophysical properties of halo-derivatives of angelicins," Journal of Photochemistry and Photobiology A: Chemistry, vol. 198, no. 1, pp. 98-105, 2008.

[35] P. Rodighiero, G. Pastorini, A. Chilin, and A. Marotto, "Synthesis of methyl derivatives of thienocoumarins and thiopyranocoumarins," Journal of Heterocyclic Chemistry, vol. 35, no. 4, pp. 847-852, 1998.

[36] P. Rodighiero, A. Guiotto, A. Chilin et al., "Angular furoquinolinones, psoralen analogs: novel antiproliferative agents for skin diseases. Synthesis, biological activity, mechanism of action, and computer-aided studies," Journal of Medicinal Chemistry, vol. 39, no. 6, pp. 1293-1302, 1996.

[37] A. Chilin, C. Marzano, and A. GuiottoF. Baccichetti, F. Carlassare, and F. Bordin, "Synthesis and biological evaluation of a new furo[2,3-h] quinolin-2(1H)-one," Journal of Medicinal Chemistry, vol. 45, no. 5, pp. 1146-1149, 2002.

[38] P. Rodighiero, G. Pastorini, A. Chilin, P. Manzini, and A. Guiotto, "Synthesis of some methylfurochromones as potential photochemotherapeutic agents," Journal of Heterocyclic Chemistry, vol. 25, no. 2, pp. 527-533, 1988.

[39] A. Chilin, P. Manzini, S. Caffieri, P. Rodighiero, and A. Guiotto, "Difurocoumarins: psoralen analogs as photochemotherapeutic agents," Journal of Heterocyclic Chemistry, vol. 38, no. 2, pp. 431-434, 2001.

[40] A. Guiotto, A. Chilin, P. Manzini, F. Dall'Acqua, F. Bordin, and P. Rodighiero, "Synthesis and antiproliferative activity of furocoumarin isosters," Farmaco (Società chimica italiana: 1989), vol. 50, pp. 479-488, 1995.

[41] E. Fabbri, M. Borgatti, G. Montagner et al., "Expression of microRNA-93 and interleukin-8 during Pseudomonas aeruginosa-mediated induction of proinflammatory responses," American Journal Respiratory Cell and Molecular Biology, vol. 50, pp. 1144-1155, 2014. 


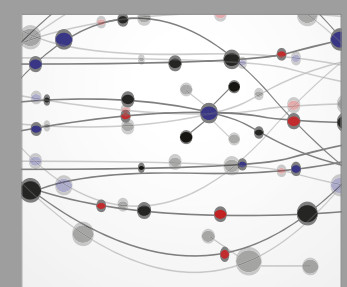

The Scientific World Journal
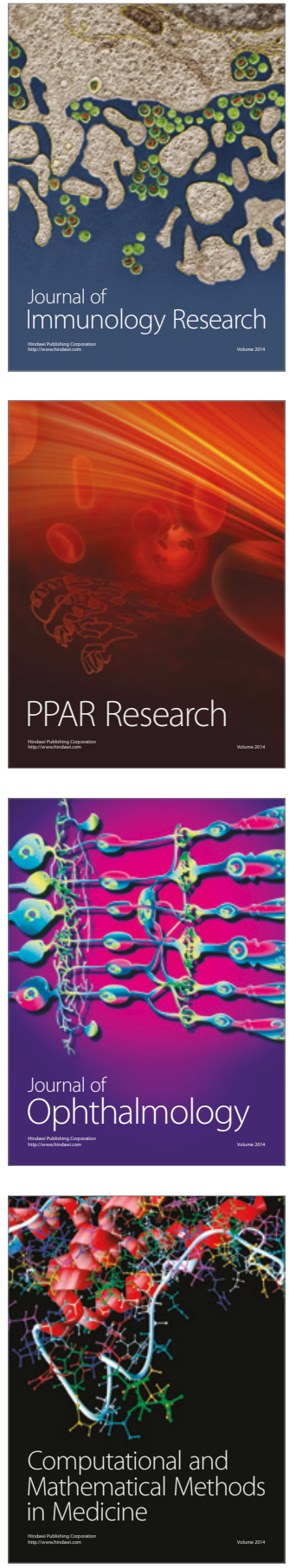

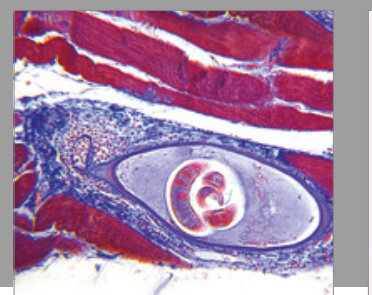

Gastroenterology Research and Practice
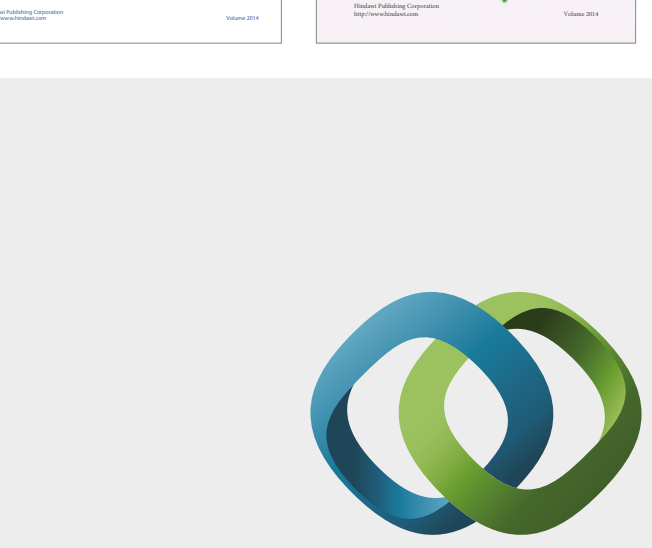

\section{Hindawi}

Submit your manuscripts at

https://www.hindawi.com
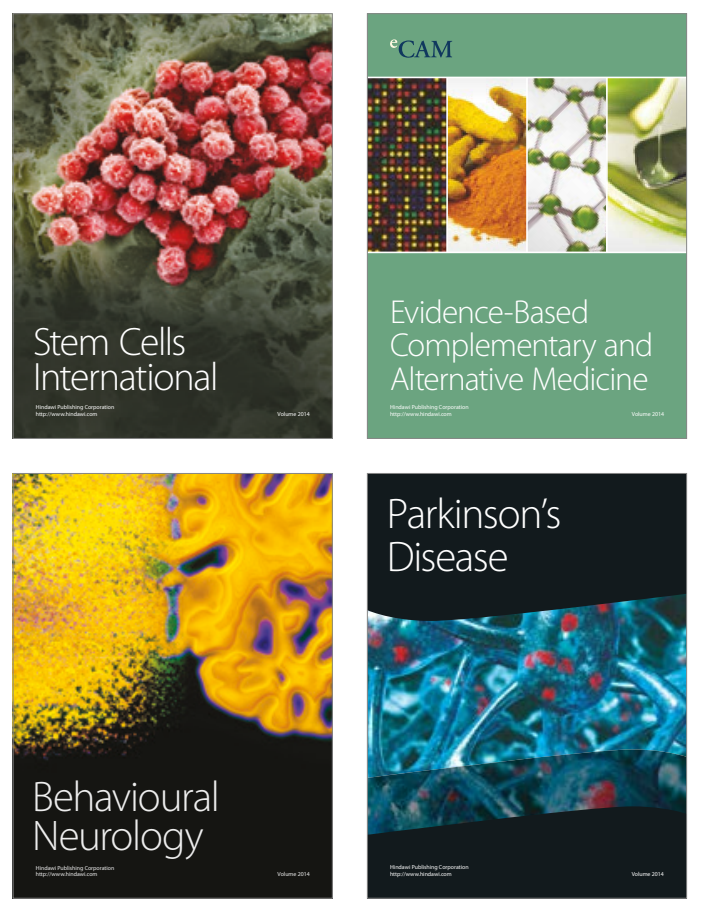
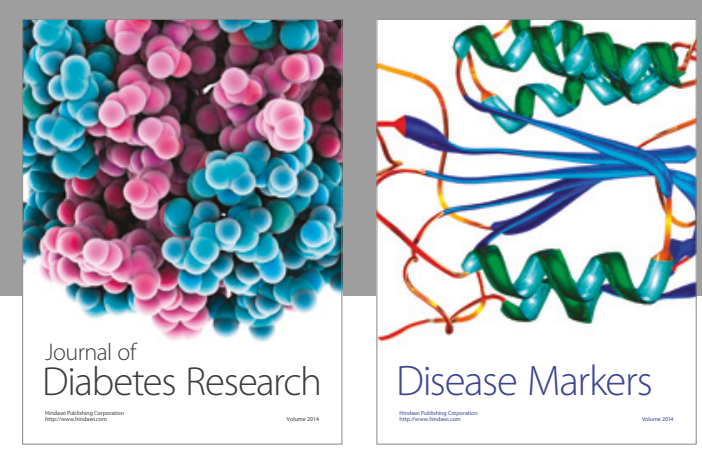

Disease Markers
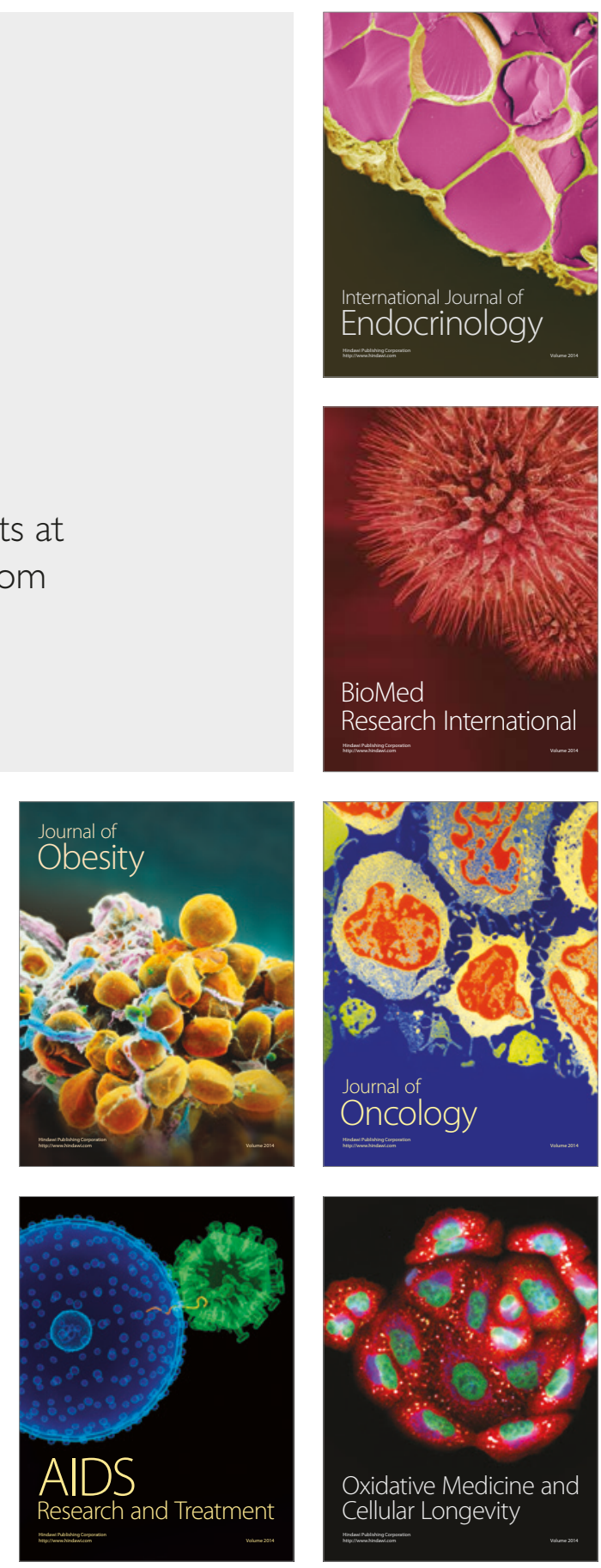